\title{
The effects of IRF6 rs2235373 polymorphism on mRNA expression changes in non-syndromic cleft lip and palate with various phenotypes
}

\author{
Saskia Lenggogeni Nasroen*\#, Ani Melani Maskoen**, Hardisiswo Soedjana**, Eky \\ Setiawan Soeria Soemantri ${ }^{* * *}$, Dany Hilmanto**** \\ *Department of Oral and Maxillofacial Surgery, Faculty of Medicine, Jenderal Achmad Yani \\ University, Indonesia \\ **Department of Oral Biology, Faculty of Dentistry, Universitas Padjadjaran, Indonesia \\ ***Department of Surgery, Faculty of Medicine, Universitas Padjadjaran, Indonesia \\ *** Department of Orthodontics, Faculty of Dentistry, Universitas Padjadjaran, Indonesia \\ *****Department of Pediatrics, Faculty of Medicine, Universitas Padjadjaran, Indonesia
}

\section{ABSTRACT}

Introduction: The IRF6 rs2235373 (C/T) is a polymorphism in the intron region that has been associated with non-syndromic cleft lip and palate (NS CLP) among some populations. Polymorphism in introns can also affect the transcription that should be detected through some changes in IRF6 mRNA expression. This study was aimed to evaluate the effects of IRF6 rs2235373 polymorphism on mRNA expression changes in NS CLP with its phenotypes which include complete unilateral (CU) CLP, complete bilateral (CB) CLP, cleft lip only (CLO), and cleft palate only (CPO). Methods: This study was a laboratory analytical study, using samples from 198 individuals in Indonesia (136 individuals with NS CL/P consisted of CU CLP $(n=42)$, CB CLP ( $n=34)$, CLO ( $n=33)$, CPO ( $n=27)$, and 62 individuals as controls). DNA was extracted from venous blood, and the segment of rs2235373 was evaluated by PCR and Sanger sequencing. mRNA expressions analysis preceded by RNA extraction from oral epithelium, then real-time (RT) PCR was performed. mRNA expression changes were analysed by Livak method and Kruskal Wallis test followed by the Mann Whitney test through CC, GT, and TT genotype. Results: The mRNA expression of TT genotype from NS CU CLP and control was 3.36 higher value than $C C$ genotype $(p=0.008)$, and the mRNA expression of $C T$ genotype from NS CB CLP and control was 0.16 lower value than CC genotype $(p=0.000)$. Conclusion: The IRF6 rs2235373 polymorphism of TT genotype tend to cause mRNA overexpression in NS CU CLP, and CT genotype tend to cause mRNA underexpression in NS CB CLP.

Keywords: Non-syndromic cleft lip and palate, NS CLP phenotype, IRF6, rs2235373, mRNA expression 


\section{INTRODUCTION}

Non-syndromic cleft lip and palate (NS CLP) is a complex congenital disability that affects $1 / 700$ children worldwide. ${ }^{1-3}$ Both genetic and environmental factors play a role in orofacial clefting, although most studies point to genetic factors as the major determinants. ${ }^{4,5}$ Few genetic variants have given rise to well-characterised molecular mechanisms in clefting pathogenesis..$^{3,6}$ NS CLP can occur as part of more than 400 syndromes (syndromic CLP) or as an isolated malformation (non-syndromic CL/P). ${ }^{7}$

Among the genetic factors, there is only one gene, Interferon Regulatory Factor (IRF6), has consistently been found to be associated with NS CLP in different populations. ${ }^{8,9}$ Single nucleotide polymorphisms (SNPs) in and around IRF6 have demonstrated a consistent association with NS CLP. $3,6,10$ IRF6 is also the causative gene for Van der Woude syndrome (VWS) and Popliteal Pterygium Syndrome (PPS). ${ }^{11,12}$

The IRF6 gene maps to chromosome 1q22 consist of 9 exons and play a role in epidermal differentiation as mice deficient for IRF6 have a hyperproliferative epidermis that fails to undergo terminal differentiation. ${ }^{13-16}$ IRF6 regulates the switch between proliferation and differentiation, and loss of function mutation/polymorphism leads to incomplete fusion from palatal shelves due to failure of medial edge epithelium (MEE) differentiation. ${ }^{17}$

Gene expression in CLP tissue from CLP patients has not been carried out much before, and this approach may potentially convey useful information on genes and families of genes interacting and playing a role in the different phenotypes in NS CLP populations. Many polymorphisms associated with NS CLP map to intragenic regions. The function of many of this polymorphisms is unknown, and their role is likely more complicated than coding mutations that can be predicted to damage or alter protein function. IFR6 rs2235373 is located in intron 7 (C/T) as the non-coding region, and we assumed that IRF6 noncoding polymorphisms also correlate with gene expression including mRNA expression.
In the DNA level, the physical position of rs2235373 is at g.20677 C > T, while in mRNA level, its location is at c. $1060+37 \mathrm{C}>\mathrm{T} .{ }^{18} \mathrm{We}$ examine the correlation between the genotypes (TT, CT and CC) of IRF6 rs2235373 and the level/ changes of mRNA expression as functional analysis in human oral epithelial from 198 individuals in Indonesia (136 individuals with NS CL/P consist of CU CLP ( $n=42)$, CB CLP $(n=34)$, CLO ( $n=$ $33), C P O(n=27)$ and 62 individuals as control). Human oral epithelial may be a suitable surrogate for functional analysis of IRF6 rs2235371 that will improve understanding of this gene and identify targets for clinical treatment and prevention of NS CLP.

Recent epidemiological research conducted by Grosen et al. in $2010^{19}$ and biological data ${ }^{20}$ suggested that cleft lip only (CLO), cleft lip and palate (CLP), and cleft palate only (CPO) may have separate genetic etiologies and should be analysed separately. One hypothesis used to explain variable phenotypes in genetic disorders is often referred to as genotype-phenotype correlation wherein the type or location of a mutation in a gene determines some aspect of phenotypes, such as severity or laterality. ${ }^{16}$ CPO and CLP seldom occur in the same families, CLO and CLP display different sex ratios and prevalence of associated malformations. ${ }^{21,22}$

However, there are also reasons why CLO might be distinct from CLP. Cleft lip has its origin as a malformation of the primary palate only, while CLP involves both the primary and secondary palates. ${ }^{23,24}$ Occasionally, a cleft lip can be found with a separated cleft of the soft but not the hard palate, which suggests two different defects. ${ }^{12,23}$ CB CLP is considered to be the most severe form of CLP and studying expression based on phenotyping of CLP suppose to reveal previously unknown associations. ${ }^{12}$

Rationalising that these epidemiological differences reflect differences in the underlying molecular processes, we compared the genotype and mRNA profiles/changes in oral epithelium removed by smear method with various type of phenotypes: CU CLP, CB CLP, CLO, CPO, and controls. This study was aimed to evaluate the 
effects of IRF6 rs2235373 polymorphism on mRNA expression changes in NS CLP with its phenotypes which include complete unilateral (CU) CLP, complete bilateral (CB) CLP, cleft lip only (CLO), and cleft palate only (CPO).

\section{METHODS}

This research was a cross-sectional laboratory analytical study. All participants were from Deutero Malay subrace as the majority of the race in Indonesia and only those individuals determined to have a non-syndromic form of CLP were included in this study. All of CLP patients were obtained based on the data from the Indonesian Cleft Lip and Palate Foundation (Yayasan Pembina Penderita Celah Bibir dan Langit-Langit (YPPCBL)) in Bandung, Indonesia. From all of the data, there was also more information about the history of environmental factors included such as the history of pregnancy, labour history, and birth weight, but we were only focusing on genetical factor, so environmental factors were excluded.

Identification as a non-syndromic form was just enough. In totally, all individuals including 198 individuals: 136 with NS CLP consist of CU CLP $(n=42)$, CB CLP $(n=34)$, CLO $(n=33)$, CPO $(n=$ 27) and 62 as controls. This study was conducted in the Molecular Biology Laboratory of Health Research Unit of Faculty of Medicine Universitas Padjadjaran Bandung/Hasan Sadikin Hospital Bandung in May 2016-January 2017.

Genotyping was performed by isolating DNA isolation with informed consent from venous blood of each subjects using a DNA isolation kit from Pharmacia, then $200 \mathrm{ng}$ of DNA template was used for Polymerase Chain Reaction (PCR) step. The PCR procedure was performed by using the primers of forward: 5'-CAGGGCTGCCGACTCTTCTA-3' and reverse: 5'-AGGAAAGCAGGAAGGTGAAAGA-3'.25 The placement strategy for the primers for the gene segment and the location of IRF6 rs2235373 gene variant can be seen in Figure 1.

CAGGGCTGCCGACTCTTCTATGGGGACCTGGGTCCCATGCCTGACCAGGAGGAGCTCTTTGGTCCCGTCAG
CCTGGAGCAGGTCAAATTCCCAGGTCCTGAGCATATTACCAATGAGAAGCAGAAGCTGTTCACTAGCAAGC
TGCTGGACGTCATGGACAGAGGACTGATCCTGGAGGTCAGCGGTCATGCCATTTATGCCATCAGGCTGTGC
CAGTGCAAGGTTACTGGTCTGGGCATGTGCCCATCACTTGTTGCTCCCAACCTGATTGAGAGACAAAA
GAAGGTCAAGCTATTTGTCTGGAAACATTCCTTAGCGGTAAGTATTTCTCAGAAAGTTGATCGTGGGAAT
CACTCTCTGGAAGTACATTCCTTCCACTATCCCTGTCTTTCACCTTCCTGCTTTCCT
$\uparrow$

Figure 1. The placement for the primers in the segment to be amplified (blue letters) and the location of IRF6 rs2235373 shown by black arrow ${ }^{26}$

DNA sequencing covering IRF6 rs2235373 was performed by using the Sanger sequencing method. The sequencing process includes the whole segment showed in Figure 1. From the sequencing result from whole samples, all nucleotide in those segment compared with normal nucleotide in gene bank by using sequence alignment program from BioEdit ${ }^{\mathrm{m}} .{ }^{26}$ The polymorphism is the form of substitution of base $\mathrm{C}$ into $\mathrm{T}$ to create 3 genotypes: TT (homozygous mutant genotype), CT (heterozygous genotype), and CC (normal genotype).

RT PCR detection of mRNA expression from IRF6 was performed through RNA isolation. After written informed consent was obtained from each individual, then epithelial cells were collected by smear method from palatal mucosa by 15 to 20 times of smear and stored in small tube consist of RNA later. Total RNA was extracted from those palatal epithelial by using Trizol ${ }^{\circledR}$ Reagent (Invitrogen, USA) and the concentration was measured by using nanodrop to ensure that there was RNA concentration obtained optimally.

The RNA was converted to CDNA by using oligo (dT) primer and Supercript ${ }^{\circledR}$ II (Invitrogen). Relative gene expression quantitation for IRF6, using GAPDH as an internal reference gene, was measured by real-time quantitative RT PCR based on the SYBR-Green method. The primers for IRF6 were 5'CGGCATAGCCCTCAACAAGAA-3' and 5'-TCCTTGGTGCCATCATACATCAG-3'; and for GAPDH were 5'-TGCTGAGTATGTCGTGGAG-3' and 5'-GTCTTCTGAGTGGCAGTGAT3', respectively. ${ }^{25}$

IRF6 mRNA expression change was analysed between genotypes (TT, CT to CT) from total NS CLP and controls, and also its phenotypes, by 
Livak method that was determined by using the comparative $\mathrm{CT}$ method $\left(2^{-\Delta \Delta C t}\right)^{27}$ and statistical analysis was performed by Kruskal Wallis test followed by Mann-Whitney test to compare groups with the $p$-value $<0.05$ was considered statistically significant.

\section{RESULTS}

The genotyping results of the initial PCR product (showed DNA band of IRF6 rs2235373 gene segment with the size of 413 base pairs (bp)) and Sanger sequencing results are shown in Figure 2.

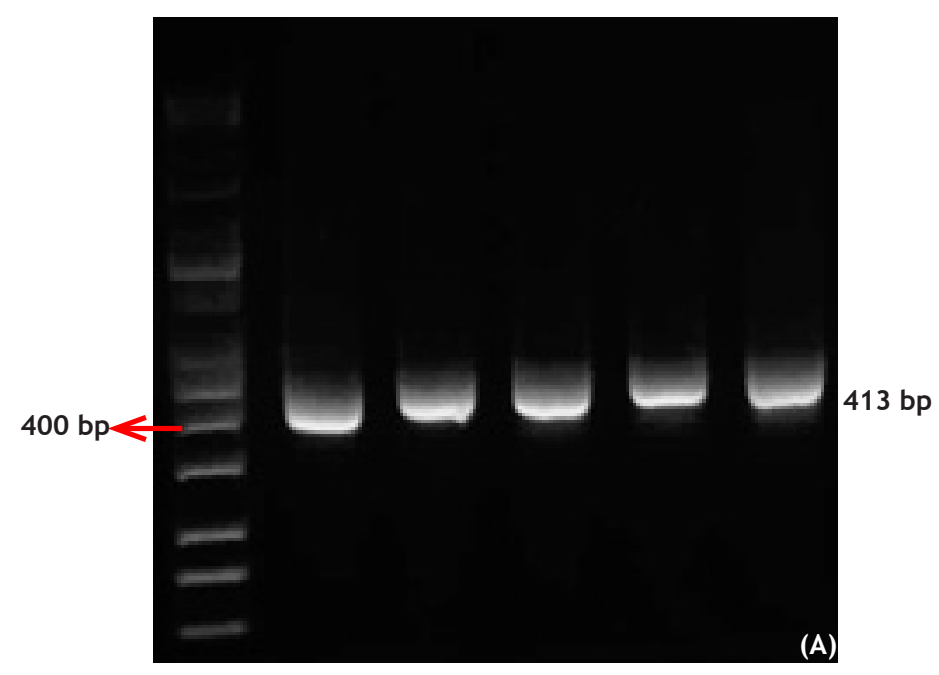

330

340

330

340

330

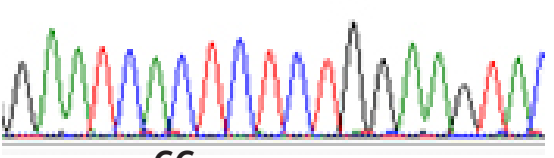

CC

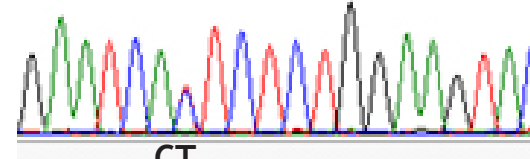

CT

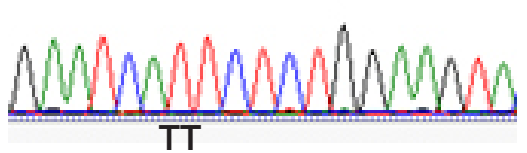

(D)

Figure 2. (A) Initial PCR product of IRF6 rs2235373 gene segment (line 1. 100 bp ladder, line 2-6. Initial PCR product of 413 bp); (B) C genotype; (C) CT genotype; (D) TT genotype

Total RNA extractions from oral epithelium by 15-20 times of smear method have been processed by real-time quantitative PCR was successful, showed by optimal RNA concentration of 1.6-2.0 (A260/A280) measured by nanodrop. IRF6 mRNA expression analysis was then analysed by relative quantification of Livak method using the comparative CT method $\left(2^{-\Delta \Delta t}\right)$ which include genotypes in NS CLP totally and each phenotype (Table 1 - 5). TT and CT genotype (polymorphism) were compared with CC genotype (nonpolymorphism).

Table 1. Relative quantification of mRNA expression IRF6 rs2235373 between CT genotype and TT genotype compared to CC genotype from total NS CLP and control

\begin{tabular}{|c|c|c|c|c|c|c|}
\hline Sample & $\begin{array}{c}\mathrm{Ct} \\
\text { IRF6 }\end{array}$ & $\begin{array}{c}\mathrm{Ct} \\
\text { GADPH }\end{array}$ & $\begin{array}{c}\Delta C t \text { GG } \\
\text { (Ct IRF6 -Ct } \\
\text { GAPDH) }\end{array}$ & $\begin{array}{c}\Delta \mathrm{Ct} \text { GA } \\
\text { (Ct IRF6 -Ct } \\
\text { GAPDH) }\end{array}$ & $\begin{array}{c}\Delta \Delta \mathrm{Ct} \\
(\Delta \mathrm{Ct} \mathrm{GA}-\Delta \mathrm{Ct} \\
\mathrm{GG})\end{array}$ & $\begin{array}{l}\text { Expression } \\
\text { value } \\
2^{-\Delta \Delta c t}\end{array}$ \\
\hline CC genotype & 31.32 & 26.49 & 4.83 & & & \\
\hline CT genotype & 34.25 & 29.40 & & 4.85 & 0.02 & 0.99 \\
\hline CC genotype & 31.32 & 26.49 & 4.83 & & & \\
\hline TT genotype & 31.93 & 27.80 & & 4.13 & -0.7 & 1.63 \\
\hline
\end{tabular}


Table 2. Relative quantification of mRNA expression IRF6 rs2235373 between CT genotype and TT genotype compared to CC genotype from NS CU CLP and control

\begin{tabular}{|c|c|c|c|c|c|c|}
\hline Sample & $\begin{array}{c}\mathrm{Ct} \\
\text { IRF6 }\end{array}$ & $\begin{array}{c}\mathrm{Ct} \\
\text { GADPH }\end{array}$ & $\begin{array}{c}\Delta \mathrm{Ct} \text { GG } \\
\text { (Ct IRF6 -Ct } \\
\text { GAPDH) }\end{array}$ & $\begin{array}{c}\Delta \mathrm{Ct} \text { GA } \\
\text { (Ct IRF6 -Ct } \\
\text { GAPDH) }\end{array}$ & $\begin{array}{c}\Delta \Delta C t \\
(\Delta C t \text { GA- } \Delta C t \\
G G)\end{array}$ & $\begin{array}{c}\text { Expression } \\
\text { value } \\
2^{-\Delta \Delta c t}\end{array}$ \\
\hline CC genotype & 31.47 & 26.06 & 5.41 & & & \\
\hline CT genotype & 39.16 & 33.38 & & 5.78 & 0.37 & 0.77 \\
\hline CC genotype & 31.47 & 26.06 & 5.41 & & & \\
\hline TT genotype & 31.93 & 27.80 & & 3.66 & -1.75 & 3.36 \\
\hline
\end{tabular}

Table 3. Relative quantification of mRNA expression IRF6 rs2235373 between CT genotype and TT genotype compared to CC genotype from NS CB CLP and control

\begin{tabular}{|c|c|c|c|c|c|c|}
\hline Sample & $\begin{array}{c}\mathrm{Ct} \\
\text { IRF6 }\end{array}$ & $\begin{array}{c}\mathrm{Ct} \\
\text { GADPH }\end{array}$ & $\begin{array}{c}\Delta C t \text { GG } \\
\text { (Ct IRF6 -Ct } \\
\text { GAPDH) }\end{array}$ & $\begin{array}{c}\Delta \mathrm{Ct} \text { GA } \\
\text { (Ct IRF6 -Ct } \\
\text { GAPDH) }\end{array}$ & $\begin{array}{c}\Delta \Delta C \mathrm{Ct} \\
(\Delta \mathrm{Ct} \mathrm{GA}-\Delta \mathrm{Ct} \\
\mathrm{GG})\end{array}$ & $\begin{array}{l}\text { Expression } \\
\text { value } \\
2^{-\Delta \Delta c t}\end{array}$ \\
\hline CC genotype & 32.30 & 29.10 & 3.20 & & & \\
\hline CT genotype & 38.56 & 32.71 & & 5.85 & 2.65 & 0.16 \\
\hline CC genotype & 32.30 & 29.10 & 3.20 & & & \\
\hline TT genotype & 29.11 & 25.87 & & 3.24 & 0.04 & 0.97 \\
\hline
\end{tabular}

Table 4. Relative quantification of mRNA expression IRF6 rs2235373 between CT genotype compared to CC genotype from NS CLO and control

\begin{tabular}{|c|c|c|c|c|c|c|}
\hline Sample & $\begin{array}{c}\mathrm{Ct} \\
\text { IRF6 }\end{array}$ & $\begin{array}{c}\mathrm{Ct} \\
\text { GADPH }\end{array}$ & $\begin{array}{c}\Delta \mathrm{Ct} \text { GG } \\
\text { (Ct IRF6 - Ct } \\
\text { GAPDH) }\end{array}$ & $\begin{array}{c}\Delta C t \text { GA } \\
\text { (Ct IRF6 -Ct } \\
\text { GAPDH) }\end{array}$ & $\begin{array}{c}\Delta \Delta \mathrm{Ct} \\
(\Delta \mathrm{Ct} \mathrm{GA}-\Delta \mathrm{Ct} \\
\mathrm{GG})\end{array}$ & $\begin{array}{l}\text { Expression } \\
\text { value } \\
2^{-\Delta \Delta c t}\end{array}$ \\
\hline CC genotype & 31.81 & 27.03 & 4.78 & & & \\
\hline CT genotype & 39.50 & 33.67 & & 5.83 & 1.05 & 0.48 \\
\hline
\end{tabular}

Table 5. Relative quantification of mRNA expression IRF6 rs2235373 between CT genotype and TT genotype compared to CC genotype from NS CPO and control

\begin{tabular}{|c|c|c|c|c|c|c|}
\hline Sample & $\begin{array}{c}\mathrm{Ct} \\
\text { IRF6 }\end{array}$ & $\begin{array}{c}\mathrm{Ct} \\
\text { GADPH }\end{array}$ & $\begin{array}{c}\Delta \mathrm{Ct} \text { GG } \\
\text { (Ct IRF6 }-\mathrm{Ct} \\
\text { GAPDH) }\end{array}$ & $\begin{array}{c}\Delta C t \text { GA } \\
\text { (Ct IRF6 -Ct } \\
\text { GAPDH) }\end{array}$ & $\begin{array}{c}\Delta \Delta \mathrm{Ct} \\
(\Delta \mathrm{Ct} \mathrm{GA}-\Delta \mathrm{Ct} \\
\mathrm{GG})\end{array}$ & $\begin{array}{c}\text { Expression } \\
\text { value } \\
2^{-\Delta \Delta c t} \\
\end{array}$ \\
\hline CC genotype & 31.00 & 25.61 & 5.39 & & & \\
\hline CT genotype & 38.85 & 32.79 & & 6.06 & 0.67 & 0.63 \\
\hline CC genotype & 31.00 & 25.61 & 5.39 & & & \\
\hline TT genotype & 32.51 & 27.66 & & 4.85 & -0.54 & 1.45 \\
\hline
\end{tabular}

From all NS CLP phenotypes, the IRF6 mRNA expression of TT genotype from NS CU CLP showed the highest value, as it was 3.36 higher than control (Table 2) according to the Livak method, means that TT genotype expressed the IRF6 mRNA 3.6 times higher than the $\mathrm{CC}$ genotype, so there was the overexpression of IRF6 mRNA expression in TT genotype from NS CU CLP. On the other hand, the
IRF6 mRNA expression of CT genotype from NS CB CLP showed the lowest value as it was 0.16 times lower than CC genotype (Table 3) according to the Livak method, so there was an underexpression of the IRF6 mRNA expression in CT genotype from NS CB CLP. Statistical analysis found that there was a significant difference of IRF6 mRNA between TT genotype and CC genotype from NS CU CLP and 
control $(p=0.008)$, and also between CT genotype and CC genotype from NS CB CLP and control $(p=$ 0.000) (Table 6 and Table 7).

Table 6. IRF6 mRNA expression comparison between CC genotype and TT genotype between NS CU CLP and control

\begin{tabular}{cccc}
\hline \multirow{2}{*}{ Variable } & \multicolumn{2}{c}{ Group } & P-value \\
\cline { 2 - 3 } & CC genotype & TT genotype & \\
\hline $2-\Delta \Delta C \mathrm{Ct}$ & & & \\
Mean \pm Std & $10.19 \pm 29.318$ & $263.38 \pm 786.878$ & \\
Median & 0.22 & 1.59 & $0.008^{* *}$ \\
Range & $0.00-146.02$ & $0.27-2628.46$ & \\
\hline
\end{tabular}

Table 7. IRF6 mRNA expression comparison between CC genotype and CT genotype between NS CB CLP and control

\begin{tabular}{cccc}
\hline \multirow{2}{*}{ Variable } & \multicolumn{2}{c}{ Group } & \multirow{2}{*}{ P-value } \\
\cline { 2 - 3 } & CC genotype & TT genotype & \\
\hline $2-\Delta \Delta C t$ & & & \\
Mean \pm Std & $15.07 \pm 31.346$ & $0.10 \pm 0.099$ & \\
Median & 0.99 & 0.06 & $0.000^{* *}$ \\
Range & $0.01-146.02$ & $0.00-0.29$ & \\
\hline
\end{tabular}

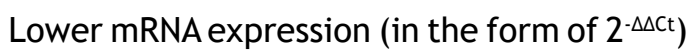
of CT genotype compared with CC genotype from NS CB CLP that showed significant relationship can be seen in Figure 3.

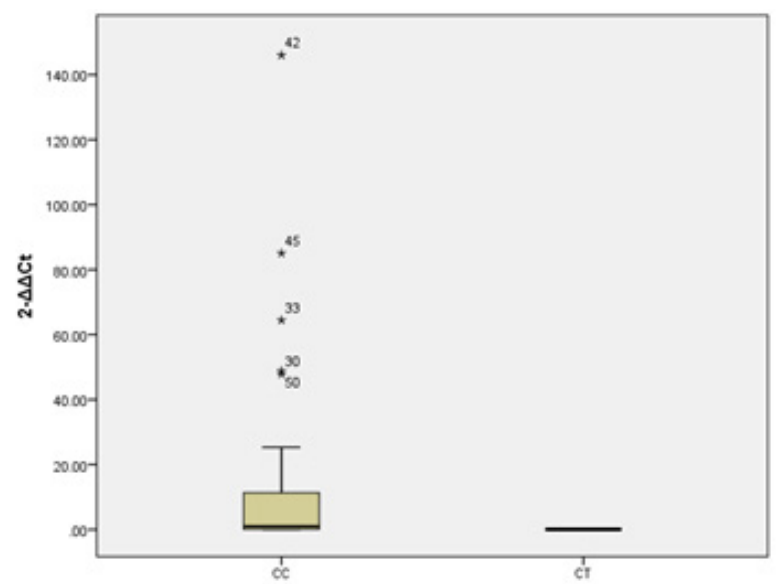

Figure 3. Significant relationship between the $C C$ and CT genotypes from NS CBCLP and IRF 6 mRNA expression (2- $\triangle \triangle C t)$. CT genotype shows significant mRNA underexpression compared with $\mathrm{CC}$ genotype

\section{DISCUSSION}

IRF6 is one of the most important genes associated with CLP development. Formation of the lip and palate in human and mouse is a complex series of cellular processes during embryonic development. ${ }^{28}$
Lip and palate are developed at different time points through common cellular processes that include proliferation, differentiation, and migration, thus it is essential to analysed IRF6 on the separate phenotype of CLP because there should be different role of IRF6 in forming lip and palate..$^{29}$ In this study, there were different results in mRNA level from each phenotype based on IRF6 rs2235373, and it means that IRF6 rs2235373 has an effect on transcription in such different manner in each NS CLP phenotype. It can be stated that IRF6 polymorphisms have a different role also in pathogenesis in CLP phenotype associated with proliferation, differentiation, and migration. However, the exact role of IRF6 in CLP pathogenesis was still cannot be elucidated.

Based on the previous study, normal craniofacial development involves the complex interaction of numerous genes, including transcription factors, growth factors, signalling molecules, and their respective receptors. IRF6 is one of the genes that direct the craniofacial processes to form, migrate, and fuse to form the face. Perturbation of this gene has the potential to alter normal craniofacial morphogenesis. . $^{30,31,32}$ As a transcription factor, the role of IRF6 in the development of lip and palate is so important and form such complex interactions and pathways with other genes such as growth factor receptors, extracellular matrix components, and cell surface receptors, but the pattern of IRF6 interaction with other genes still cannot be explained yet. ${ }^{33}$

This study emphasised to evaluate the effect of IRF6 rs2235373 on mRNA expression changes in NS CLP with its phenotype because we considered that mRNA expression could be the first step to reveal IRF6 role in pathogenesis in NS CLP with its phenotype; thus we evaluated this gene through intron polymorphism of rs2235373.

However, before we discuss more the result, there were some reasons on why we chose oral epithelium as the sample for evaluating mRNA changes. Firstly, because IRF6 is the most important gene in epithelial proliferation. Based on previous research in animal models during the fetal period indicated that IRF6 regulates epitheliocytes proliferation, which has a key role in the formation of the oral periderm. Secondly, because IRF6 is strongly expressed in some areas in body parts, including oral epithelium. 
Studies in an animal model had revealed that IRF6 was expressed in the facial primordium before and during morphogenesis of the primary palate, as it was expressed in the epithelium of the lateral and medial nasal prominences as well as the epithelium of the maxillary and mandibular prominences. ${ }^{12,29,34}$ Preliminary findings in mice had also revealed the IRF6 expression in the MEE of fusing secondary palatal shelves, tooth buds, hair follicles, and skin. ${ }^{34,35}$ Also, IRF6 was strongly expressed in the MEE throughout palatal development. ${ }^{29,35}$ During the postnatal period, as in the adult, high IRF6 expression was also detected in hair follicles, palatal rugae, tooth germ and thyroglossal duct, external genitalia, and skin throughout the body. ${ }^{11,12,25}$ In adult, IRF6 expression is still required in the proliferation and differentiation of keratinocyte and epidermis suprabasal layers. ${ }^{15}$

Palatal development in the fetal period, and wound healing in the postnatal period/adulthood are both require epithelial compartment to migrate and proliferate thus we assumed that the functional role of IRF6 still can be detected from oral epithelium of adult/postnatal period based on IRF6 function in epidermal differentiation as a critical process of keratinocytes that responsible for building the functional epidermis. As IRF6 expressed strongly in oral epithelium, we took the sample from oral epithelium in the palatal region which considered to be keratinised based on the fundamental consideration that mRNA expression from NS CLP cases could be detected in the areas that are expressed (oral mucous region). ${ }^{12}$

IRF6 rs2235373 also associates on NS CLP risk over some populations. ${ }^{36}$ However, we did not analyse the polymorphism as the risk factor of NS CLP and its phenotype among Indonesian because analysing the polymorphism associated with mRNA expression changes will give more explanation on IRF6 functional role in NS CLP with its phenotype. Dissecting the role of IRF6 and the potential effects of polymorphisms required a comprehensive study regarding its expression pattern during embryonic development and how that pattern is regulated. It was shown that IRF6 is expressed in the epithelium of the lateral and medial nasal prominences as well as in the epithelium of the maxillary and mandibular prominences. Also, IRF6 was strongly expressed in the medial edge epithelium throughout palatal development. ${ }^{29,37}$ To understand the mechanistic basis of how polymorphism is associated with a particular phenotype, it is necessary to find out the polymorphism functionality (i.e., whether it alters the function of a gene or set of genes). In most cases, the role of an associated polymorphism is not defined and must be presumed as an effect on the gene that contains such polymorphism. Most common polymorphisms are potential regulatory polymorphisms located in noncoding regions, including promoter/upstream, downstream and intron regions, that may affect the transcription. ${ }^{37}$ Intron and untranslated regions transcribed as RNA that may affect transcription, RNA splicing, stability or translation, or in intergenic regions of unknown function. $38,39,40$

A further level of regulation applies during splicing. This regulation may be altered when the splicing signals in the introns are mutated, where the splice factors bind. Mutations or polymorphisms in this region may lead to differentially spliced or truncated products that may not be functional or even more or less different functions. ${ }^{40}$ The phenotype of intronic alterations may depend on how important is the affected protein or expression levels. IRF6 polymorphism of rs2235373 is in intron 7 , which is a non-coding region, in the form of substitution of base $\mathrm{C}$ into $\mathrm{T}$. This polymorphism may have influenced the splicing process. If the splicing process happens earlier or do not happen may cause the immature mRNA, so mRNA cannot exit from the cytoplasm.

IRF6 is predominantly present in the cytoplasm, but there is only very few information in the literature on how IRF6 rs2235373 polymorphism influences functional role in mRNA expression among NS CLP phenotypes. ${ }^{41}$ The phenotypic features are a result of an imbalance between the proliferation and differentiation of precursor cells during development of ectodermderived structures. ${ }^{42}$ The functional role of IRF6 polymorphism to be associated with NS CLP has not been yet defined thus our study evaluated IRF6 mRNA expression, not in embryonic development, but from the oral epithelium of NS CLP patients with its phenotype out of embryonic development phase. NS CLP phenotype will describe more about IRF6 function, whether this gene will also influence the severity of NS CLP. 
As presented in Table $1-5$, there were under and overexpression of mRNA levels among all subjects, which include NS CLP with its phenotype and control. The more detailed result could not be seen in general of NS CLP (Table 1). However, it was seen in NS CLP phenotype that includes NS CU CLP, NS CB CLP, NS CLO, and NS CPO. According to the Livak method analysis, the real mRNA overexpression can be found in NS CU CLP (Table 2), and the real mRNA underexpression can be found in NS CB CLP (Table 3). In NS CU CLP (Table 2), homozygous mutant of TT genotype expressed mRNA 3.36 times/being overexpressed than homozygous normal of CC genotype as control $(p=0.008)$, while in NS CB CLP (Table 3), heterozygous mutant of $\mathrm{CT}$ genotype expressed mRNA was 0.16 lower and was an underexpression than homozygous normal of CC genotype as control $(p=0.000)$. These two results were contradictive. NS CB CLP is the most severe form of NS CLP, means that IRF6 mRNA underexpression may have a contribution to the severity of NS CLP.

There was a study revealed the effect of IRF6 rs642961 on mRNA expression changes in NS CLP which showed mRNA underexpression result, but IRF6 rs642961 is on promoter region. ${ }^{25}$ There wasn't any previous study which also analyses IRF6 rs2235373 polymorphism associated with mRNA expression changes in other populations, so there were still no data to compare this finding. Based on the underlying theory as a result of some previous studies, the mechanism or how the pathogenesis of IRF6 mRNA expression could affect the NS CLP has not yet been defined. Based on the basic theory also, during early differentiation, $\Delta$ Np63 (p63 isoform) promotes transcriptional activation of IRF6, and the IRF6 protein, in turn, promotes $\Delta$ Np63 degradation. ${ }^{42}$ This feedback regulation may play an essential role in controlling the proliferation and differentiation of keratinocytes. ${ }^{42}$

IRF6 expression is regulated through both SMAD and p38 MAPK pathways. In the absence of TGFB receptor type II (TBRII), IRF6 expression decreases. $\triangle N p 63$ expression increases in the absence of TBRIl resulting in reduced p21 gene (which encodes a cyclin-dependent kinase (CDK) inhibitor) expression in the palatal epithelium. Altered TGFB-IRF6- $\triangle$ Np63-p21 activity results in the persistence of the MEE. ${ }^{43}$ IRF6 is a mediator of TGFB3 in the regulation of the EMT and apoptosis during palatal fusion. A schematic model outlines the TGFB 3-IRF6-EMT-apoptosis pathways during palatal fusion. TGFB3 upregulates the expression of IRF6 and enhances its nuclear translocation, which then seems to alter the expression of SNAI2 as epithelial mesenchymal transformation (EMT) regulator. Changes in SNAI2 expression represses Plakophilin, and ZO-1 (epithelial markers) expression and induces the EMT, which is essential to the process of palatal fusion.

Ectopic expression of IRF6 was able to rescue the TgfB3-blocked palatal fusion, and the SNAI2 knockdown then blocked this rescue effect. ${ }^{41}$ Also, IRF6 has been reported to regulate $\Delta$ Np63 protein degradation, which will result in p21 expression induction and MEE apoptosis; this is also crucial to the palatal fusion process.12,41 IRF6 promotes the decay of $\Delta \mathrm{Np} 63$, allowing keratinocytes to exit the cell cycle and differentiate. ${ }^{42,44}$ IRF6 induces downregulation of $\triangle \mathrm{Np} 63$ in human keratinocytes as in the adult. The developmental defects were also observed in IRF6 of mutant mice was considered as the result from inability of IRF6 mutant cells to exit the cell cycle, leading to an undifferentiated hyperproliferative epidermis. ${ }^{42}$ Thus, underexpression mRNA level in NS CBCLP in our study could alter the TGFB-IRF6- $\triangle$ Np63-p21 activity results in the persistence of the MEE. On the other hand, mRNA expression that tends to increase or being overexpression by TT genotype in NS CU CLP could be caused by an alteration in the SNAI2 and TGFB3 that leads to an altered ectopic expression of IRF6 to rescue the TGFB3-blocked palatal fusion. Overexpression of IRF6 leads to hyperproliferation of epidermis that causes the failure of termination in cell differentiation.

However, such weaknesses still existed in this study. Other evaluation through another method, such as immunohistochemistry, was not carried out to compare mRNA expression result, and there was a limitation in the sample size. In the future study, we suggest that there should be comparison from mRNA expression in the embryonic development process in a larger sample size.

\section{CONCLUSION}

The IRF6 rs2235373 polymorphism of TT genotype tends to cause mRNA over expression in 
NS CU CLP and CT genotype tends to cause mRNA under expression in NS CB CLP. These results mean that this polymorphism influences the functional role of this gene, which is different in each NS CLP phenotypes. In this study, there is no influence from gender status because it has been considered that CLP is not linked to the sex chromosome.

\section{REFERENCES}

1. Mossey PA, Little J, Munger RG, Dixon MJ, Shaw WC. Cleft lip and palate. Lancet. 2009; 374(9703): 1773-85. DOI: 10.1016/S01406736(09)60695-4

2. Nasroen SL, Tajrin A, Fauziah PN, Maskoen AM, Soemantri ES, Soedjana $H$, et al. TGFB3 / SfaN1 gene variant and the risk factor of nonsyndromic cleft palate only among Indonesian patients. Cell Mol Biol (Noisy-legrand). 2017; 63(2): 88-91. DOI: 10.14715/ $\mathrm{cmb} / 2017.63 .2 .13$

3. Leslie EJ, Marazita ML. Genetics of Cleft Lip and Cleft Palate. Am J Med Genet C Semin Med Genet. 2013; 163(4): 246-258. DOI: $10.1002 /$ ajmg.c.31381

4. Christensen K, Mitchell LE. Familial recurrence-pattern analysis of nonsyndromic isolated cleft palate--a Danish Registry study. Am J Hum Genet. 1996; 58(1): 182-90.

5. Murray JC. Gene/environment causes of cleft lip and/or palate. Clin Genet. 2002; 61 (4): 24856. DOI: $10.1034 / j .1399-0004.2002 .610402 . x$

6. Dixon MJ, Marazita ML, Beaty TH, Murray JC. Cleft lip and palate: understanding genetic and environmental influences. Nat Rev Genet. 2011; 12(3): 167-78. DOI: 10.1038/nrg2933

7. Gorlin LJ, Cohen MM, Hennekam RCM. Syndromes of the head and neck. $4^{\text {th }}$ ed. Oxford: Oxford University Press; 2001.

8. Blanton SH, Cortez A, Stal S, Mulliken JB, Finnell RH, Hecht JT. Variation in IRF6 contributes to nonsyndromic cleft lip and palate. Am J Genet A. 2005; 137A(3): 259-62.

9. Zucchero T, Cooper ME, Maher BS, DaackHirsch S, Nepomuceno B, Ribeiro L, et al. Interferon regulatory factor 6 (IRF6) gene variants and the risk of isolated cleft lip or palate. N Engl J Med. 2004; 351(8): 769-80. DOI: 10.1056/NEJMoa032909
10. Jugessur A, Farlie PG, Kilpatrick N. The genetics of isolated orofacial clefts: from genotypes to subphenotypes. Oral Dis. 2009; 15(7): 437-53. DOI: $10.1111 / j .1601-0825.2009 .01577 . x$

11. Kondo S, Schutte BC, Richardson RJ, Bjork BC, Knight AS, Watanabe Y, et al. Mutations in IRF6 cause Van der Woude and popliteal pterygium syndromes. Nat Genet. 2002; 32(2): 285-9. DOI: $10.1038 / \mathrm{ng} 985$

12. Nasroen SL, Maskoen AM, Soemantri ESS, Soedjana $\mathrm{H}$, Hilmanto D. The IRF6 mRNA expression changes in oral epithelium of non syndromic cleft lip and palate with various phenotypes. Ind J Oral Maxillofac Surg. 2017; 4: 3-11.

13. Ingraham CR, Kinoshita $A$, Kondo $S$, Yang B, Sajan S, Trout KJ, et al. Abnormal skin, limb and craniofacial morphogenesis in mice deficient for interferon regulatory factor 6 (IRF6). Nat Genet. 2006; 38(11): 1335-40. DOI:

\subsection{8/ng1903}

14. Richardson RJ, Dixon J, Malhotra S, Hardman MJ, Knowles L, Boot-Hanford RP, et al. IRF6 is a key determinant keratinocyte proliferationdifferentiation switch. Nat Genet. 2006; 38(11): 1329-34. DOI: 10.1038/ng1894

15. Biggs LC, Rhea L, Schutte B, Dunnwald M. Interferon Regulatory Factor 6 is Necessary, but Not Sufficient, for Keratinocyte Differentiation. J Invest Dermatol. 2012; 132(1): 50-8. DOI: $10.1038 /$ jid.2011.272

16. Leslie EJ. Advances in understanding the genetic architecture of cleft lip and palate disorders [dissertation]. lowa: University of lowa; 2012.

17. Kousa YA, Schutte BC. Toward an Orofacial Gene Regulatory Network. Dev Dyn. 2016; 245(3): 220-32. DOI: 10.1002/dvdy.24341

18. Salahshourifar I, Wan Sulaiman WA, Halim AS, Zilfalil BA. Mutation screening of IRF6 among families with non-syndromic oral clefts and identification of two novel variants: Review of literature. Eur J Med Genet. 2012; 55(6-7): 389-93. DOI: $10.1016 / j$.ejmg.2012.02.006

19. Rahimov F, Marazita ML, Visel A, Cooper ME, Hitchler MJ, Rubini M, et al. Disruption of an AP-2alpha binding site in an IRF6 enhancer is associated with cleft lip. Nat Genet. 2008; 40(11): 1341-7. DOI: 10.1038/ng.242 
20. Ludwig KU, Mangold E, Herms S, Nowak S, Reutter H, Paul A, et al. Genome-wide metaanalyses of nonsyndromic cleft lip with or without cleft palate identify six new risk loci. Nat Genet. 2012; 44(9): 968-71. DOI: 10.1038/ ng. 2360

21. Fogh-Andersen P. Inheritance of harelip and cleft palate. Copenhagen: NYT Nordisk Forlag; 1942.

22. Pegelow M, Peyrard-Janvid M, Zucchelli M, Fransson I, Larson O, Kere J, et al. Familial non-syndromic cleft lip and palate - analysis of the IRF6 gene and clinical phenotypes. Eur J Orthod. 2008; 30(2): 169-75. DOI: 10.1093/ ejo/cjm097

23. Harville EW, Wilcox AJ, Lie RT, Vindenes $\mathrm{H}$, Abyholm F. Cleft Lip and Palate versus Cleft Lip Only: Are They Distinct Defects?. Am J Epidemiol. 2005; 162(5): 448-53. DOI: 10.1093/aje/kwi214

24. Kreiborg S, Hermann NV. Craniofacial morphology and growth in infants and young children with cleft lip and palate. In: Wyszynski DF. Cleft lip and palate: From origin to treatment. New York: Oxford University Press; 2002. p. 87-97.

25. Pan Y, Ma J, Zhang W, Du Y, Niu Y, Wang M, et al. IRF6 polymorphisms are associated with nonsyndromic orofacial clefts in a Chinese Han population. Am J Med Genet A. 2010; 152A(10): 2505-11. DOI: 10.1002/ajmg.a.33624

26. Ensembl Asia. [homepage on internet]. Cambridge: retrieved 2015 October; [about 2 screens]. Available from https://asia. ensembl.org/index.html

27. Livak KJ, Schmittgen TD. Analysis of relative gene expression data using real-time quantitative PCR and the 2(-Delta Delta C(T)) Method. Methods. 2001; 25(4): 402-8. DOI: 10.1006/meth.2001.1262

28. Fakhouri WD, Rhea L, Du T, Sweezer E, Morrison H, Fitzpatrick D, et.al. MCS9.7 Enhancer activity is Highly, but not Completely, Associated with Expression of Irf6 and p63. Dev Dyn. 2012; 241(2): 340-9. DOI: 10.1002/ dvdy.22786

29. Washbourne BJ, Cox TC. Expression profiles of cIRF6, CLHX6 and CLHX7 in the facial primordia suggest specific roles during parimary palatogenesis. BMC Dev Biol. 2006; 6: 18. DOI: 10.1186/1471-213X-6-18

30. Riley BM, Mansilla MA, Ma J, Daack-Hirsch S, Maher BS, Raffensperger LM, et al. FGF signaling contributes to cleft lip and palate. Proc Natl Acad Sci U S A. 2007; 104(11): 4512-

7. DOI: $10.1073 /$ pnas.0607956104

31. Riley BM, Murray JC. Sequence evaluation of FGF and FGFR gene conserved non-coding elements in non-syndromic cleft lip and palate cases. Am J Med Genet A. 2007; 143A(24): 3228-34. DOI: 10.1002/ajmg.a.31965

32. Tian M, Shi JY, Wu M, Wang Y, Li L, Liu Y, et.al. Overexpression of mouse TTF-2 gene causes cleft palate. J Cell Mol Med. 2012; 16(10): 23628. DOI: $10.1111 / j .1582-4934.2012 .01546 . x$

33. Cox TC. Taking it to the max: the genetic and developmental mechanisms coordinating midfacial morphogenesis and dysmorphology. Clin Genet. 2004; 65(3): 163-76. DOI: 10.1111/j.0009-9163.2004.00225.x

34. Smane L, Pilmane M. IRF6, RYK, and PAX9 Expression in Facial Tissue of Children with Cleft Palate. Int J Morphol. 2015; 33(2): 64752. DOI: 10.4067/S0717-95022015000200037

35. Knight AS, Schutte BC, Jiang R, Dixon MJ. Developmental expression analysis of the mouse and chick orthologues of IRF6: the gene mutated in Van der Woude syndrome. Dev Dyn. 2006; 235(5): 1441-7. DOI: 10.1002/ dvdy.20598

36. Park JW, Mclntosh I, Hetmanski JB, Jabs EW, Vander Kolk CA, Wu-Chou YH, et al. Association between IRF6 and nonsyndromic cleft lip with or without cleft palate in four populations. Genet Med. 2007; 9(4): 219-27. DOI: 10.1097GIM.0b013e3180423cca

37. Chorley BN, Wang X, Campbell MR, Pittman GS, Noureddine MA, Bell DA. Discovery and verification of functional single nucleotide polymorphisms in regulatory genomic regions: current and developing technologies. Mutat Res. 2008; 659(1-2): 147-57. DOI: 10.1016/j. mrrev.2008.05.001

38. Sadee W, Wang D, Papp AC, Pinsonneault JK, Smith RM, Moyer RA, et al. Pharmacogenomics of the RNAworld: structural RNApolymorphisms in drug therapy. Clin Pharmacol Ther. 2011; 89(3): 355-65. DOI: 10.1038/clpt.2010.314 
39. Liao PY, Lee KH. From SNPs to functional polymorphism: the insight into biotechnology applications. Biochem Eng J. 2010; 49(2): 14958. DOI: $10.1016 /$ j.bej.2009.12.021

40. Albert PR. What is a functional genetic polymorphism? Defining classes of functionality. J Psychiatry Neurosci. 2011; 36(6): 363-5. DOI: 10.1503/jpn.110137

41. Ke CY, Xiao WL, Chen CM, Lo LJ, Wong FH. IRF6 is the mediator of TGFB3 during regulation of the epithelial mesenchymal transition and palatal fusion. Sci Rep. 2015; 5: 12791. DOI: $\underline{10.1038 / \text { srep } 12791}$
42. Moretti F, Marinari B, Lo lacono N, Botti E, Giunta A, Spallone G, et al. A regulatory feedback loop involving p63 and IRF6 links the pathogenesis of 2 genetically different human ectodermal dysplasias. J Clin Invest. 2010; 120(5): 1570-7. DOI: $10.1172 / \mathrm{JCl} 40267$

43. Iwata J, Suzuki A, Pelikan RC, Ho TV, SanchezLara PA, Urata $M$, et al. Smad4-Irf6 genetic interaction and TGFB-mediated IRF6 signaling cascade are crucial for palatal fusion in mice. Development. 2013; 140: 1220-30. DOI: 10.1242/dev.089615

44. Gritli-Linde A. p63 and IRF6: brothers in arms against cleft palate. J Clin Invest. 2010; 120(5): 1386-9. DOI: $10.1172 / \mathrm{JCl} 42821$ 